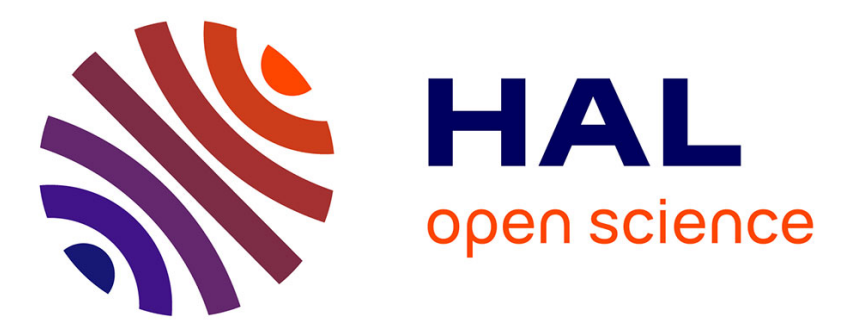

\title{
Optimization of Truck Platoon Wander Patterns Based on Thermo-Viscoelastic Simulations to Mitigate the Damage Effects on Road Structures
}

\author{
Paul Marsac, Juliette Blanc, Olivier Chupin, Thomas Gabet, Ferhat
} Hammoum, Navneet Garg, Mai Lan Nguyen

\section{To cite this version:}

Paul Marsac, Juliette Blanc, Olivier Chupin, Thomas Gabet, Ferhat Hammoum, et al.. Optimization of Truck Platoon Wander Patterns Based on Thermo-Viscoelastic Simulations to Mitigate the Damage Effects on Road Structures. 6th International Conference on Accelerated Pavement Testing, Sep 2021, NANTES, France. pp. 100-107, 10.1007/978-3-030-55236-7_11. hal-02942266

\section{HAL Id: hal-02942266 \\ https://hal.science/hal-02942266}

Submitted on 17 Sep 2020

HAL is a multi-disciplinary open access archive for the deposit and dissemination of scientific research documents, whether they are published or not. The documents may come from teaching and research institutions in France or abroad, or from public or private research centers.
L'archive ouverte pluridisciplinaire HAL, est destinée au dépôt et à la diffusion de documents scientifiques de niveau recherche, publiés ou non, émanant des établissements d'enseignement et de recherche français ou étrangers, des laboratoires publics ou privés. 


\title{
Optimization of Truck Platoon Wander Patterns Based on Thermo-Viscoelastic Simulations to Mitigate the Damage Effects on Road Structures
}

\author{
Paul Marsac ${ }^{1(\bowtie)}$, Juliette Blanc ${ }^{2}$, Olivier Chupin ${ }^{2}$, Thomas Gabet ${ }^{1}$, \\ Ferhat Hammoum ${ }^{1}$, Navneet Garg $^{3}$, and Mai Lan Nguyen ${ }^{2}$ \\ ${ }^{1}$ MAST-MIT, Univ Gustave Eiffel, IFSTTAR, F-44344 Bouguenais, France \\ \{paul.marsac, thomas. gabet, \\ ferhat.hammoum\}@univ-eiffel.fr \\ 2 MAST-LAMES, Univ Gustave Eiffel, IFSTTAR, F-44344 Bouguenais, France \\ \{juliette. blanc, olivier. chupin, \\ mai-lan.nguyen\}@univ-eiffel.fr \\ ${ }^{3}$ FAA William J. Hughes Technical Center, Egg Harbor Township, \\ NJ 08405, USA \\ navneet.garg@faa.gov
}

\begin{abstract}
The concept of truck platooning is to take advantage of the connectivity technologies and automated driving support systems to link trucks in close formation (convoy) in order to increase transport efficiency, reduce fuel consumption and gas emissions while improving road safety. However, closely guided trucks following each other could have a different impact on road structures than the usual truck traffic. Notably, different studies with traffic simulators highlight the significant effect of the wander pattern of traffic on the damage observed on test road structures. On the other hand, the positioning systems could offer the opportunity to choose an optimized wander pattern of the trucks within the platoons, especially designed to mitigate the overall damage. In this context, the study reported in this paper addresses, through numerical simulations, the multi-loading effects of truck platoons on road structures for different configurations of wander patterns. The aggressiveness of these patterns is evaluated on the basis of the viscoelastic response of the pavement structures (strain field) computed using software ViscoRoute $\subset$ 2.0. Finally, recommendations on the choice of wander pattern configurations to be tested on APT facilities are proposed.
\end{abstract}

Keywords: Truck platooning $\cdot$ Numerical simulation $\cdot$ Traffic damage $\cdot$ Traffic wander pattern

\section{Introduction}

Truck platooning consists in making trucks driving in close formation, without drivers, by using the connectivity technologies and automated driving support. It may increase transport efficiency, reduce fuel consumption and gas emissions while improving road safety. However, closely following guided trucks could have a different impact on road infrastructures than the usual truck traffic. Different experimental studies performed by 
means of fatigue carrousels (Kerzrého et al. 2012) or other traffic simulators highlighted the significant effect of the wander pattern of traffic on the damage observed on tested road structures (Hayhoe et al. 2004; Simonin and Hornych 2018), particularly in the case where there is no wandering.

In the framework of the French rational road design procedure, load wandering is taken into account in an implicit manner. Indeed, the coefficients used to correlate computations and field results are set up by means of experimental tests performed on the fatigue carrousel at Université Gustave Eiffel using a fixed load wandering. In the design method, the wandering coefficient is fixed and the same for any design.

When the design procedure was adapted to airfields pavements, the wandering coefficient was explicitly taken into account, to adapt to the specificity of airplane loads wandering and then to better characterize the damage due to airplanes traffic. Contrarily to airplanes, truck platoon may concentrate the loads on a given lane instead of spreading them as airplanes can do.

In this context, the first step of this study consists in taking advantage of numerical simulations to get an order of magnitude of the impact of truck platoon on service life of infrastructures. Strains are computed at the bottom of the asphalt concrete layer, for different configurations of wander patterns. Viscoelastic computation is performed by means of the software Viscoroute 2.0. Then, damages induced by the different strain fields are assessed using the French design method (Corte and Goux 1996) and compared to quantify the potential impact on the road structure durability.

\section{Numerical Simulations}

The numerical simulations are performed with the software ViscoRouteC 2.0.

\subsection{Overview of ViscoRoute $\mathbb{2} .0$}

ViscoRouteC 2.0 (Chabot et al. 2010; Chupin et al. 2010; Hammoum et al. 2010) is a software dedicated to the computation of the dynamic response of multilayer pavements subjected to loads moving at constant speed (quasi-stationary assumption). The material layers can be modeled as linear elastic (non-bituminous layers) or viscoelastic according to the Huet (Huet et al. 1963; Huet 1999) or Huet-Sayegh (Sayegh 1965) models which are well adapted to represent the thermo-sensitive behavior of asphalt concrete. The computation is performed by means of a semi-analytical approach that consists in seeking the solution to the mechanical problem first in the wavenumber domain prior to returning to the spatial domain by running the Fast Fourier Transform. The calculation outputs are the displacement, strain and stress fields in the structure.

\subsection{Road Structure}

The road structure chosen is composed of 2 courses of bituminous materials on an infinite elastic roadbed. A constant Poisson's ratio $(v=0.35)$ is assumed for the 3 materials. The Young modulus of the roadbed is $120 \mathrm{MPa}$. The base-course is a $20 \mathrm{~cm}$ thick layer of high modulus asphalt (named EME) and the surface-course is $2.5 \mathrm{~cm}$ 
thick layer of thin asphalt (named BBTM). The viscoelastic properties of the materials of the 2 asphalt layers are modeled with a Huet-Sayegh model. This model (Fig. 1) is composed of an elastic spring connected in parallel to 2 parabolic dampers in series with an elastic spring. $E_{O}$ is the static elastic modulus, $E_{\infty}$ is the instantaneous elastic modulus, $k$ and $h$ are exponents of the parabolic dampers $(1>h>k>0)$ and $\delta$ is a positive non-dimensional coefficient balancing the contribution of the first damper (1). $\theta$ represents the temperature and $\tau$ is a response time parameter which account for the equivalence principle between frequency and temperature (2). The values of the HuetSayegh model parameters for the 2 materials are given in Table 1 . The simulation is made for a temperature of $30^{\circ} \mathrm{C}$.

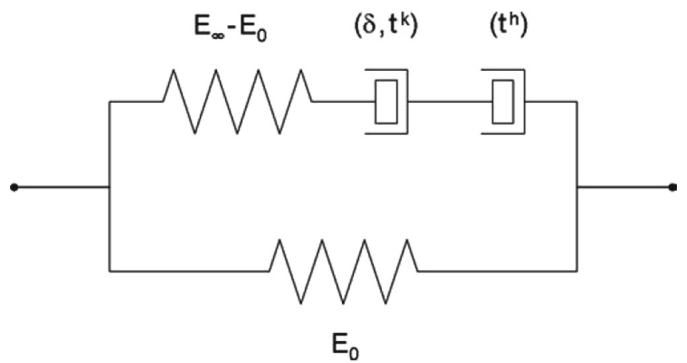

Fig. 1. Schematic representation of the Huet-Sayegh model

$$
\begin{gathered}
E^{*}(\omega \tau(\theta))=E_{0}+\frac{E_{\infty}-E_{0}}{1+\delta(i \omega \tau(\theta))^{-k}+(i \omega \tau(\theta))^{-h}} \\
\tau(\theta)=e^{\left(A_{0}+A_{1} \theta+A_{2} \theta^{2}\right)}
\end{gathered}
$$

Table 1. Values of the Huet-Sayegh model parameters for the 2 asphalt materials

\begin{tabular}{l|l|l|l|l|l|l|l|l}
\hline & $E_{O}(M P a)$ & $E_{\infty}(M P a)$ & $k$ & $h$ & $\delta$ & $A_{O}$ & $A_{1}$ & $A_{2}$ \\
\hline $\begin{array}{l}\text { Surface course } \\
\text { (BBTM) }\end{array}$ & 19 & 19644 & 0.213 & 0.628 & 2.535 & 3.072 & -0.382 & 0.00165 \\
\hline \begin{tabular}{l} 
Base course (EME) \\
\hline
\end{tabular} & 22 & 31008 & 0.186 & 0.599 & 2.064 & 5.865 & -0.388 & 0.0020 \\
\hline
\end{tabular}

\subsection{Loading Configuration}

The loading configurations are chosen in order to simulate a platoon of 3 trucks closely following each other with $2 \mathrm{~m}$ interspace. Only one wheel path is considered as the 2 wheel paths are symmetrical. The loading is $32.5 \mathrm{kN}$ for the tractor wheels and $40 \mathrm{kN}$ for the semi-trailer tridem wheels. The wandering effect is simulated through variations of the transversal distance $d$ between the wheel paths of each individual truck according to Fig. 2. 


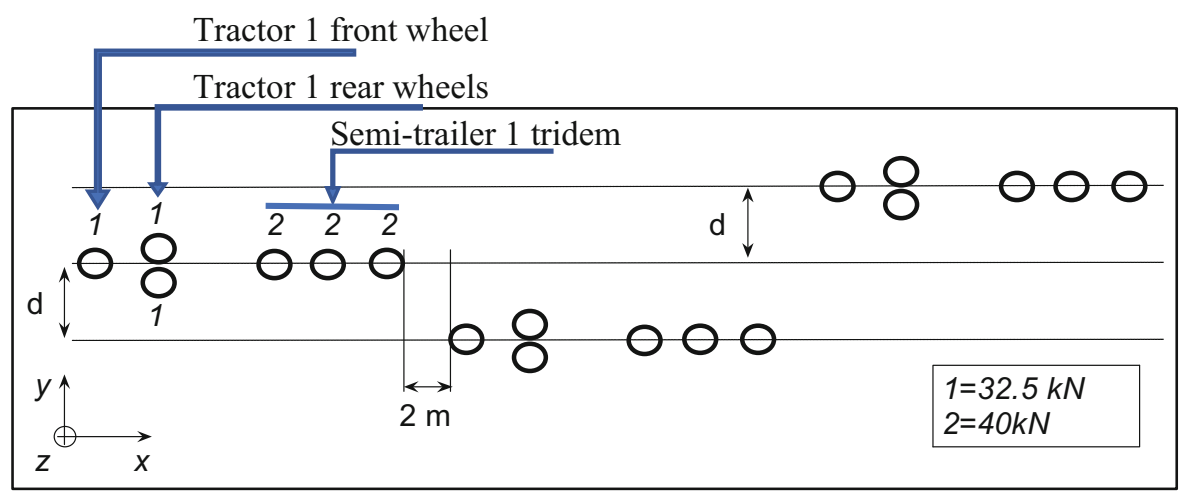

Fig. 2. Loading configurations: platoon of 3 tractor/semi-trailer trucks with $2 \mathrm{~m}$ interspace distance and variable transversal distance $d$ between the wheel paths of each truck

The simulation are performed in an orthogonal coordinate system $(x, y, z)$ as mentioned in Fig. 2. The transversal strain (cyy) field at the bottom of the EME base course $(z=-22.5 \mathrm{~cm})$ is calculated with ViscoRoute(C) 2.0 for 8 loading conditions corresponding to values of the transversal distance $d$ ranging from 0 to $35 \mathrm{~cm}$ with an incremental step of $5 \mathrm{~cm}$. The speed of the trucks is fixed at $20 \mathrm{~m} / \mathrm{s}$.

\subsection{Strain Field Results}

The envelope (maximum value on a transverse profile) of the strain (cyy) along the longitudinal $(x)$ axis is plotted in Fig. 3. For a better readability, only 3 simulations are plotted for wandering distances of $d=0,15$ and $25 \mathrm{~cm}$ because the trend is almost linear between 0 and $25 \mathrm{~cm}$ and the envelopes are similar for $d>25 \mathrm{~cm}$. A view of the end of the curve, corresponding to the 3 wheels of the last semi-trailer, is plotted in Fig. 4. The Fig. 3 highlights the cumulative effect due to the lack of wandering. No wander leads to reach a transversal strain of $142 \mu$ strains. For a wander of 15 or $25 \mathrm{~cm}$, the transversal strain at the bottom of the AC layer reaches approximately $125 \mu$ strains, as it is shown in the Fig. 4.

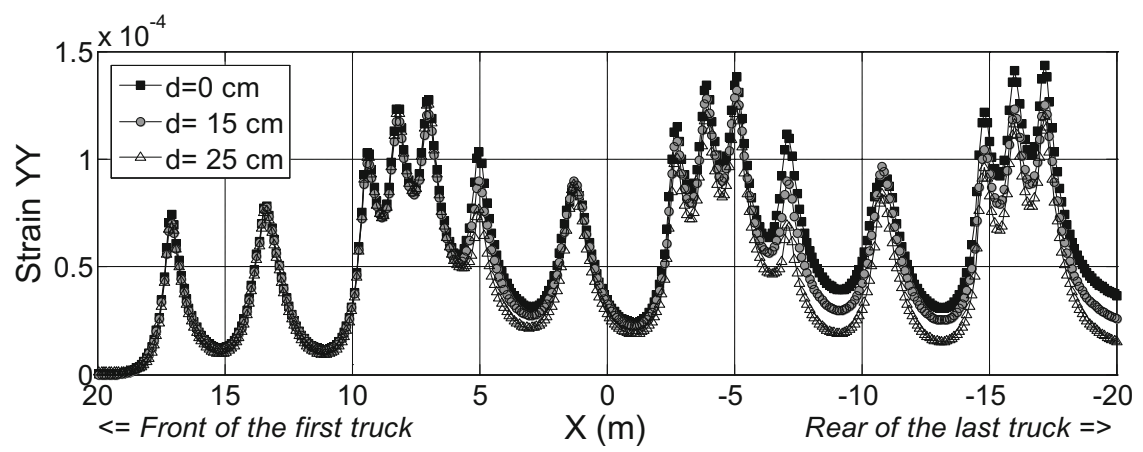

Fig. 3. Envelopes (maximum value on a transverse profile) of the strain (cyy) along the longitudinal $(x)$ axis for $d=0,15$ and $25 \mathrm{~cm}$ 


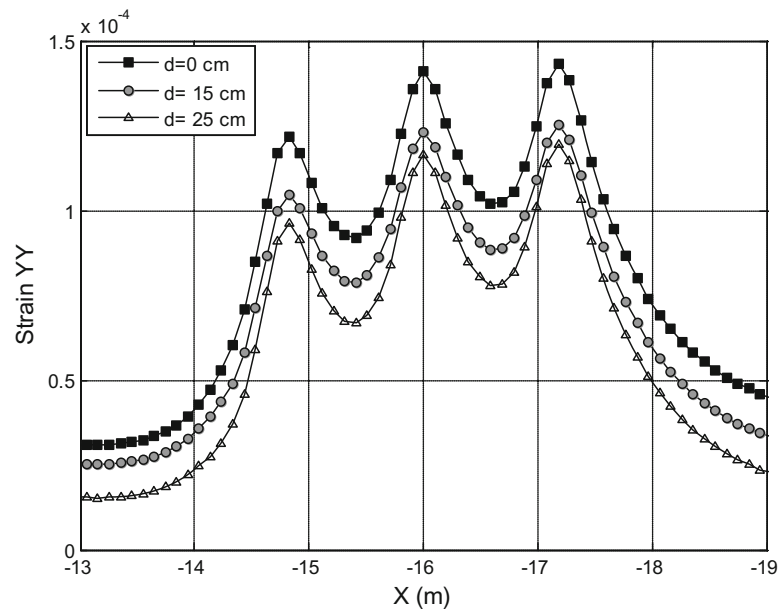

Fig. 4. Envelopes (maximum value on a transverse profile) of the strain (cyy) along the longitudinal ( $x$ ) axis for $d=0,15$ and $25 \mathrm{~cm}$. Zoom on the end of the curve (trailer of the last truck)

In the same way, the envelopes (maximum value on a longitudinal profile) of the strain (cyy) along the transverse $(y)$ axis are plotted in Fig. 5.

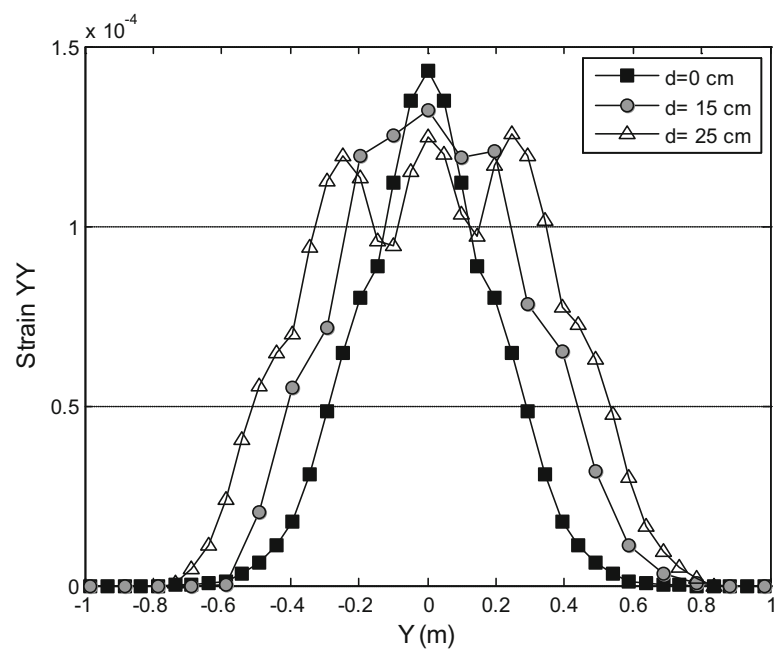

Fig. 5. Envelopes (maximum value on a longitudinal profile) of the strain (cyy) along the transverse (y) axis for $d=0,15$ and $25 \mathrm{~cm}$

Without wandering $(d=0 \mathrm{~cm})$, the peaks of Eyy are necessarily concentrated on the same longitudinal profile at $y=0$. For $d=25 \mathrm{~cm}$ the maxima are distributed on 3 profiles and the cumulative effect is less important with a maximum peak value for $\varepsilon y y$ 
$12 \%$ lower than for $d=0 \mathrm{~cm}$. Thus we can already assume that wandering can significantly mitigate the damage effect of a platoon.

\section{Damage Effect Calculation}

To quantify the different damage effects, a calculation is performed according to the damage calculation method used in the pavement structure design software Alizé (Balay 2013). The damage $D$ of a platoon is considered as proportional to the sum along a longitudinal profile of the positive strain cyy peaks power the slope of the fatigue law (3). An example of the local peaks and inter-peaks minima of cyy along a longitudinal profile is plotted in Fig. 6.

$$
D=K^{1 / b}\left(\sum_{i=1}^{i=n} \varepsilon_{d i}^{-1 / b}-\sum_{i=1}^{i=n-1} \varepsilon_{u l i, i+1}^{-1 / b}\right)
$$

With:

$K$ : the constant of the fatigue law

$-1 / b$ : the slope of the fatigue law (in this study, a value of $-1 / b=5$ is assumed) $\varepsilon_{d i}$ : the $i$ order local peak of $\varepsilon y y$ on a longitudinal profile

$\varepsilon_{u l i, i+1}$ : the $i$ order local inter-peaks minimum of cyy on a longitudinal profile

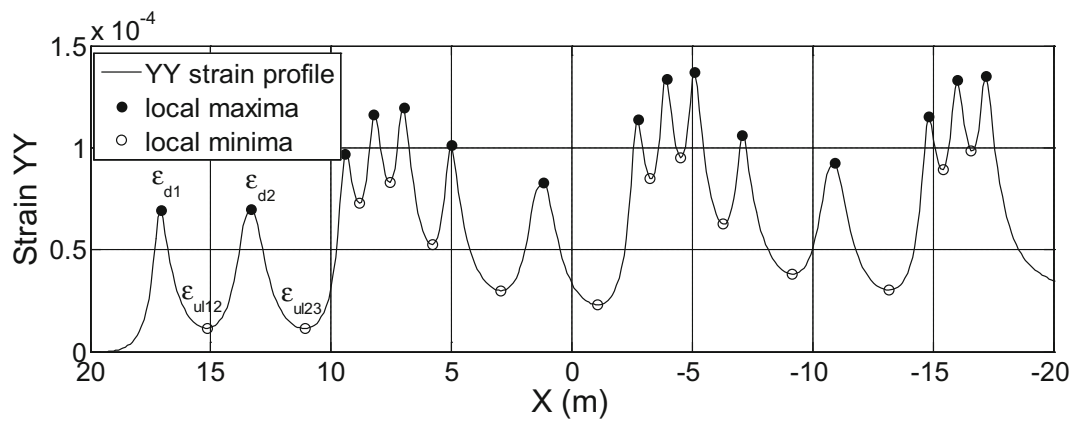

Fig. 6. Local peaks and inter-peaks minima of eyy along a longitudinal profile

The second term of the right side of Eq. (3), proportional to $D$, is plotted along the transverse direction in Fig. 7. 


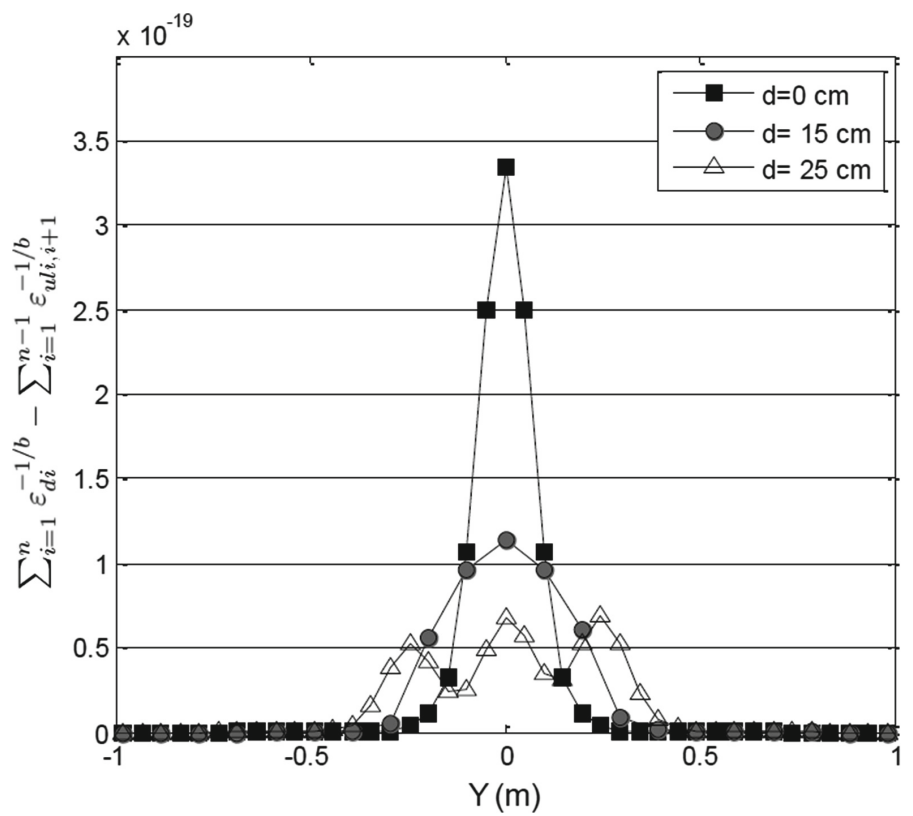

Fig. 7. Second term of the right side of Eq. (3), proportional to $D$, along the transverse direction

The lack of wandering induces an increase of damage caused by a platoon of 3 trucks. A ratio of about 6 is found between the damage (Fig. 7) without wandering (squares) and the damage with a wandering with $d=25 \mathrm{~cm}$ (triangles).

\section{Conclusion}

This numerical analysis highlights the significant potential effect of the wander pattern of the truck platoons on the damage induced on road structures. A ratio of about 6 is found between the damage induced by a 3 trucks platoon without wandering and the damage induced by the same platoon with an optimized wander pattern. This emphasizes the importance of considering the wander pattern in the positioning systems in order to conciliate the benefits associated with the platooning and the road network durability. For that purpose, the numerical simulation software ViscoRoute $C$ 2.0 can contribute to improve accelerated pavement tests efficiency by pre-selecting relevant wander patterns according to the features of the platoons considered before experimental simulations on APT facilities or implementation on positioning systems.

Acknowledgements. The activity presented in the paper is part of the research project ENSEMBLE co-funded by the European Union under the Horizon 2020 (H2020) Research and Innovation Program (grant agreement No 769115). 


\section{References}

Balay, J.M.: Manuel d'utilisation ALIZÉ - LCPC version 1.5 (2013)

Chabot, A., Chupin, O., Deloffre, L., Duhamel, D.: ViscoRoute 20: a tool for the simulation of moving load effects on asphalt pavement. Road Mater. Pavement Des. 11(2), 227-250 (2010). https://doi.org/10.1080/14680629.2010.9690274

Chupin, O., Chabot, A., Piau, J.M., Duhamel, D.: Influence of sliding interfaces on the response of a layered viscoelastic medium under a moving load. Int. J. Solids Struct. 47(25-26), 34353446 (2010). https://doi.org/10.1016/j.ijsolstr.2010.08.020

Corté, J.F., Goux, M.T.: Design of pavement structures: the French technical guide. Transp. Res. Rec. 1539, 116-124 (1996). https://doi.org/10.1177/0361198196153900116

Hammoum, F., Chabot, A., Saint Laurent, D., Chollet, H., Vulturescu, B.: Effects of accelerating and decelerating tramway loads on bituminous pavement. Mater. Struct. 43, 1257-1269 (2010). https://doi.org/10.1617/s11527-009-9577-9

Hayhoe, G.F., Garg, N., Dong, M.: Permanent deformations during traffic tests on flexible pavements at the National Airport Pavement Test Facility. In: Airfield Pavements: Challenges and New Technologies, pp. 147-169 (2004)

Huet, C.: Etude par une méthode d'impédance du comportement viscoélastique des matériaux hydrocarbonés. Ph.D. thesis Université de Paris, France (1963)

Huet, C.: Coupled size and boundary-condition effects in viscoelastic heterogeneous and composite bodies. Mech. Mater. 31(12), 787-829 (1999). https://doi.org/10.1016/s0167-6636 (99)00038-1

Kerzrého, J.P., Hornych, P., Chabot, A., Deloffre, L., Trichet, S., Coirier, G., Gouy, T.: Evaluation of the aggressiveness of different multi-axle loads using APT tests. In: Jones, D., Harvey, J., Al-Qadi, I., Mateos, A., (eds.) Advances in Pavement Design through Full-scale Accelerated Pavement Testing. CRC Press, London, pp. 505-517. https://doi.org/10.1201/ b13000-62, http://www.crcnetbase.com/doi/pdf/10.1201/b13000-62

Sayegh, G.: Contribution à l'étude des propriétés viscoélastiques des bitumes purs et des bétons bitumineux. Ph.D. thesis, Faculté des Sciences de Paris, France (1965)

Simonin, J.M., Hornych, P., Nguyen, M.L.: E-Way Corridor - DF4- Conception et construction des systèmes routiers, Phase 3 Options d'aménagement des voies d'autoroute actuelles (2018) 